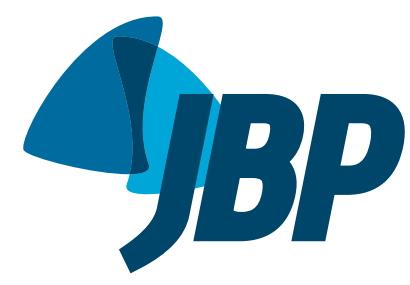

1. Programa de Pós-Graduação em Medicina e Ciências da Saúde, Escola de Medicina, Pontifícia Universidade Católica do Rio Grande do Sul - PUCRS - Porto Alegre (RS) Brasil.

2. Programa de Pós-Graduação em Pneumologia, Hospital São Lucas, Escola de Medicina, Pontifícia Universidade Católica do Rio Grande do Sul - PUCRS - Porto Alegre (RS) Brasil.

a. (iD http://orcid.org/0000-0003-3704-7913

b. (iD) http://orcid.org/0000-0003-0916-9171

c. (iD) http://orcid.org/0000-0002-4343-025X

Submitted: 25 February 2017 Accepted: 3 September 2017.

Study carried out at the Hospital São Lucas Pontifícia Universidade Católica do Rio Grande do Sul, Porto Alegre (RS) Brasil.

\section{Theoretical pneumococcal vaccine coverage: analysis of serotypes isolated from inpatients at a tertiary care hospital}

\author{
Cynthia Rocha Dullius ${ }^{1, a}$, Luciana Zani²,b, José Miguel Chatkin²,c
}

\begin{abstract}
Objective: To evaluate Streptococcus pneumoniae serotypes isolated from an inpatient population at a tertiary care hospital, in order to determine the theoretical coverage of the 13-valent pneumococcal conjugate vaccine (PCV13) and the 23-valent pneumococcal polysaccharide vaccine (PPV23). Methods: This was a cross-sectional study involving 118 inpatients at the Hospital São Lucas, in the city of Porto Alegre, Brazil, whose cultures of blood, cerebrospinal fluid, or other sterile body fluid specimens, collected between January 2005 and December 2016, yielded pneumococcal isolates. The theoretical vaccine coverage was studied in relation to the serotypes identified in the sample and their relationship with those contained in the pneumococcal vaccines available in Brazil. Results: The majority of the population was male ( $n=66 ; 55.9 \%$ ), with a median age of 57 years (interquartile range: 33-72 years). The most common manifestation was pneumonia, and the pneumococcus was most commonly isolated from blood cultures. More than one fourth of the study population had some degree of immunosuppression ( $n=34 ; 28.8 \%)$. Of the total sample, 39 patients $(33.1 \%$ ) died. There were no significant associations between mortality and comorbidity type, ICU admission, or need for mechanical ventilation. The theoretical vaccine coverage of PPV23 alone and PCV13 plus PPV23 was $31.4 \%$ and $50.8 \%$, respectively. Conclusions: If the patients in this sample had been previously vaccinated with PCV13 plus PPV23, theoretically, 50.8\% of the cases of invasive pneumococcal disease that required hospital admission could potentially have been prevented. Invasive pneumococcal disease should be prevented by vaccination not only of children and the elderly but also of adults in their economically productive years, so as to reduce the socioeconomic costs, morbidity, and mortality still associated with the disease, especially in underdeveloped countries.
\end{abstract}

Keywords: Pneumococcal infections; Serotyping; Tertiary care centers.

\section{INTRODUCTION}

Acute respiratory infections cause approximately four million deaths per year globally, being the leading cause of death in developing countries. ${ }^{(1)}$ Streptococcus pneumoniae is the most common etiologic agent of community-acquired bacterial respiratory tract infections. (2) Invasive pneumococcal disease (IPD) accounts for a portion of all S. pneumoniae infections, being defined as the contamination of sterile body fluids with this agent, that is, as the isolation of $S$. pneumoniae from cultures of blood, cerebrospinal fluid, pleural fluid, or other normally sterile body sites.

IPD has high socioeconomic costs, ${ }^{(3)}$ with increased (acute and late) morbidity and mortality, ${ }^{(4)}$ especially in susceptible populations (children, the elderly, patients with cardiac comorbidities, patients with pulmonary comorbidities, and immunosuppressed patients in general). ${ }^{(5)}$ IPD continues to be the leading vaccine-preventable cause of death in children under 5 years of age, even with the significant change in the epidemiology of this disease after the implementation of routine vaccination in Australia(6) and in western European countries. ${ }^{(7)}$

In the USA, after the marketing of the 7-valent pneumococcal conjugate vaccine in the 2000s, there was a significant reduction in the number of cases of IPD in children up to 5 years of age and in adults over 50 years of age because of the herd effect. There was also a replacement of serotypes in the community by others not previously included. (8) With the introduction of the 13-valent pneumococcal conjugate vaccine (PCV13) in that same country, the number of hospitalizations for IPD in children under 5 years of age was further reduced, and there was also some effect on hospitalizations for IPD among some adult age groups. ${ }^{(9)}$

Therefore, the present study was carried out to evaluate the microbiological characteristics of community-acquired invasive S. pneumoniae strains in inpatients at a tertiary care hospital in order to determine the theoretical coverage of the pneumococcal vaccines currently available in BrazilPCV13 and 23-valent pneumococcal polysaccharide vaccine (PPV23)-as well as to quantify possible prevention. It is important to conduct studies to determine the serotypes 
of IPD and the theoretical coverage of the available vaccines so that new formulations of these vaccines can eventually be developed, including serotypes that have not yet been covered, herd effect can be determined, and the serotypes involved in IPDs in each location can be identified.

The difference between the two vaccines lies in the type of immunity conferred: PPV23 bases its ability to confer immunity on the pneumococcal polysaccharide capsule (B cell-dependent immune response), whereas PCV13 elicits a T cell-dependent immune response (long-term immune memory). ${ }^{(10)}$ Chemical and serological differences between capsules are the basis for grouping pneumococci into different serotypes. ${ }^{(11,12)}$ Each serotype is distinguished by the chemical structure of the capsule, by immune response, that is, by the ability to react with specific antibodies against the capsular antigen, and by other related specific mutations. However, not all of the more than 90 pneumococcal serotypes identified cause disease. Some serotypes are more strongly related to bacterial resistance, and others are more strongly related to deaths and invasive disease. (13) PCV13 includes serotypes 1, 3, 4, 5, 6A, 6B, 7F, 9V, 14, 18C, 19A, 19F, and 23F. PPV23 includes all serotypes included in PCV13 except serotype 6A, plus another 11 serotypes: $2,8,9 \mathrm{~N}, 10 \mathrm{~A}, 11 \mathrm{~A}, 12 \mathrm{~F}$ 15B, 17F, 20, 22F, and 33F.

In view of these considerations, the present investigation was devised to find some answers on a more local level in an attempt to determine similarities to and differences from what is already known on this subject at the regional and national level.

\section{METHODS}

This was a cross-sectional, descriptive, analytical study involving inpatients at a tertiary care hospital in the city of Porto Alegre, Brazil, in whom laboratory testing of sterile body fluids detected S. pneumoniae. All specimens were collected between January 2005 and December 2016. Antimicrobial susceptibility was assessed using the Kirby-Bauer method on MuellerHinton agar (bioMérieux, Marcy l'Étoile, France) supplemented with blood, and the antimicrobials tested included erythromycin, levofloxacin, oxacillin, sulfamethoxazole/trimethoprim, and vancomycin. All cases in which a halo of inhibition $\geq 20 \mathrm{~mm}$ was observed for oxacillin $(1 \mu \mathrm{g})$ were considered susceptible to penicillin. Those in which a halo of inhibition $\leq 19 \mathrm{~mm}$ was observed for oxacillin were submitted to penicillin ETEST $^{\circledR}$ (bioMérieux) to determine the minimum inhibitory concentration. The criteria for determining the antibiotics to be tested, as well as the criteria for interpreting halos of inhibition and susceptibility or resistance to penicillin after ETEST $^{\circledR}$, followed the recommendations of the Clinical and Laboratory Standards Institute. ${ }^{(14)}$ Clinical and demographic data were collected by review of patient medical records.

Vaccine coverage data were not available from medical records, so we theorized vaccine coverage and correlated it with the serotypes identified in the sample, that is, we sought to relate each identified serotype to the potential coverage of the vaccines available in Brazil. Pneumococcal cultures were sent to the Adolfo Lutz Institute, in the city of São Paulo, Brazil, via the Central Laboratory of the State of Rio Grande do Sul, for serotyping. A decision was made to include patients with immunosuppression in the study sample, because the objective was to determine whether the serotypes identified in the sample were covered by the vaccines available. Categorical variables were expressed as frequencies and proportions, symmetric quantitative variables were expressed as means and standard deviations, and asymmetric quantitative variables were expressed as medians and interquartile ranges (IQRs). Quantitative data were compared by analysis of homogeneity of variance (Cochran's test), whereas nominal data were compared by using McNemar's test. The level of significance was set at $a=0.05$. Data were analyzed with SPSS Statistics, version 21.0 (IBM Corporation, Armonk, NY, USA). The study was approved by the Scientific Committee of the School of Medicine and the Research Ethics Committee of the Pontifical Catholic University of Rio Grande do Sul (Protocol no. 56187816.5.0000.5336).

\section{RESULTS}

A total of 147 pneumococcal strains were initially considered for analysis, but only 118 were analyzed (losses included 15 dead strains, 6 missing samples, 5 contaminated samples, and 3 samples with pending results). The most common serotypes were, in decreasing order, 19A, 3, 12F, 8, 14, and 11A (Figure 1 ). Figure 2 presents the proportion of serotypes in the study sample.

The patients studied were mostly male $(n=66$; $55.9 \%$ ), with a median age of 57 years (IQR: $33-72$ years). The most common manifestation was pneumonia ( $n=90 ; 76.3 \%)$, followed by meningitis ( $n=12$; $10.2 \%$ ). The most common culture was blood culture ( $n=101 ; 85.6 \%)$, followed by cerebrospinal fluid culture $(n=15 ; 13.7 \%)$. Overall mortality was $33.1 \%$ ( $n=39$ ). Immunosuppressed patients (HIV and/or neoplasm and/or use of corticosteroids and/or use of immunosuppressants) accounted for $28.8 \%(n=34)$ of the sample. In the study population, 19 patients (16.1\%) had pulmonary comorbidities, and 58 (49.2\%) had previous hospital admissions. ICU admission and mechanical ventilation (MV) were necessary in 41 cases (34.7\%) and 28 cases (23.7\%), respectively (Table 1 ).

When comparing the presence/absence of comorbidities as a risk factor for mortality, as well as for ICU admission, MV, and tracheostomy, we found no statistically significant differences (Table 2). There was no significant correlation between mortality and the different serotypes.

In terms of antimicrobial susceptibility, the proportion of samples resistant to sulfamethoxazole/trimethoprim, erythromycin, penicillin, and levofloxacin was $37.3 \%$, 


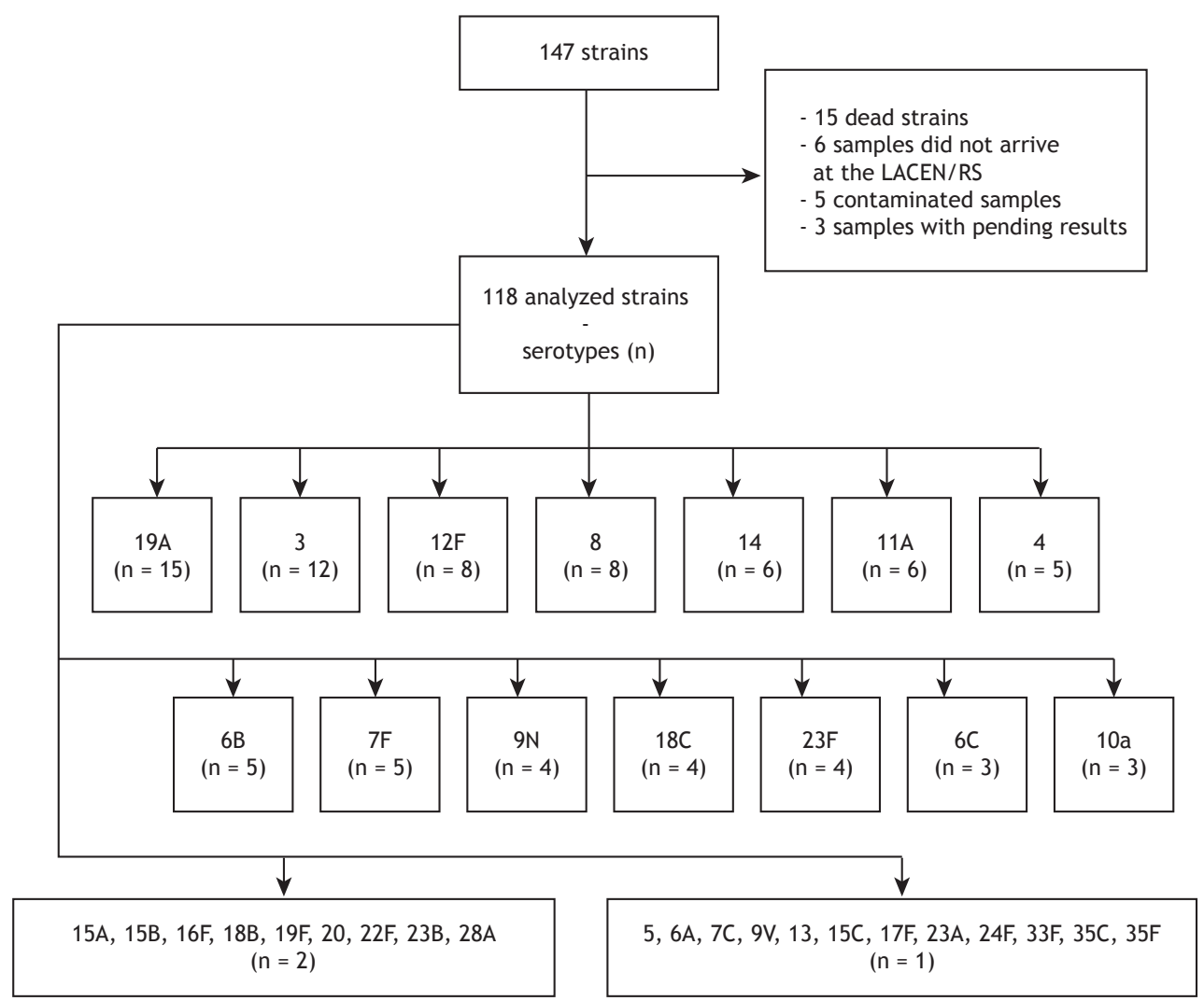

Figure 1. Flowchart of analysis of serotypes in the study population. LACEN/RS: Laboratório Central do Estado do Rio Grande do Sul (Central Laboratory of the State of Rio Grande do Sul).

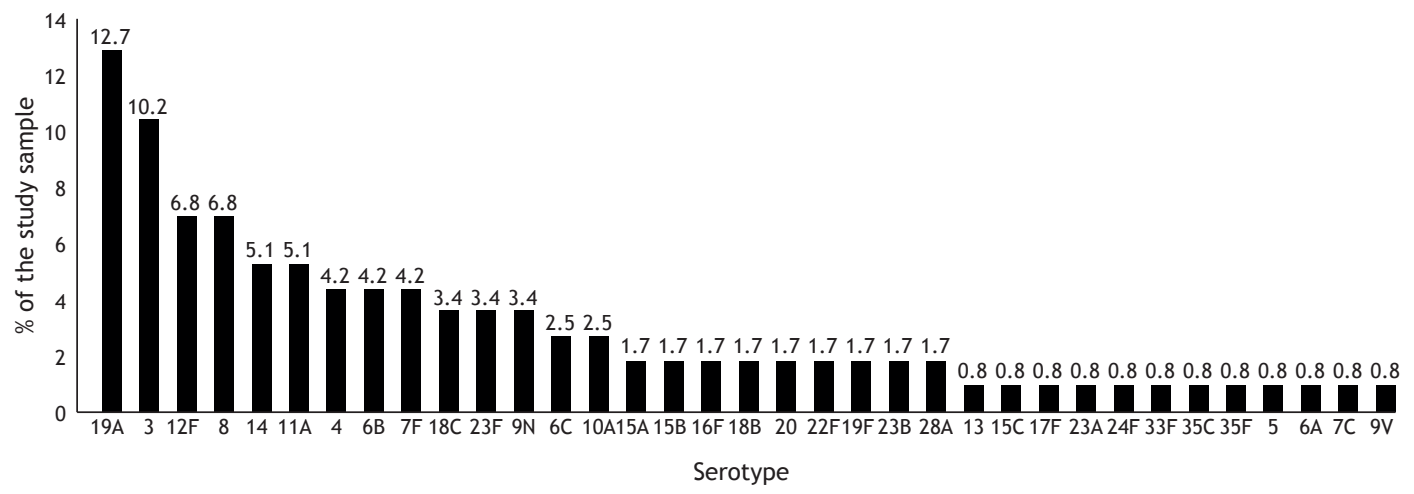

Figure 2. Frequency of serotypes in the study sample.

$17.8 \%, 9.3 \%$, and $1.7 \%$, respectively. There were no cases of resistance to vancomycin. Multiple comparisons with McNemar's test showed that the strains were less susceptible to sulfamethoxazole/trimethoprim and more susceptible to vancomycin and levofloxacin.

Table 3 presents the theoretical coverage of PCV13 and PPV23 alone, as well as in combination, in relation to mortality. No statistically significant differences were detected $(p=0.508)$.

\section{DISCUSSION}

The present study evaluated data on serotyping of pneumococci associated with IPD in inpatients at a hospital that services a considerable portion of the population with IPD in a regional capital city in Brazil. Analysis of pneumococcal serotypes was possible in $118(80.27 \%)$ of the cases in the total sample.

The most common serotypes in our sample were, in decreasing order, $19 \mathrm{~A}, 3,12 \mathrm{~F}, 8,14$, and $11 \mathrm{~A}$, with serotype $19 \mathrm{~A}$ accounting for $12.7 \%$ of the total sample. The literature on Brazilian strains tends to indicate serotype 14 as the most common. ${ }^{(15-19)}$ Usually, serotypes associated with increased mortality include serotypes $3,6 \mathrm{~A}, 6 \mathrm{~B}, 8,19 \mathrm{~F}, 23 \mathrm{~F}$, and $6 \mathrm{C}$, whereas those associated with decreased mortality include serotypes $23 \mathrm{~A}, 35 \mathrm{~B}$, and $35 \mathrm{~F}{ }^{(20)}$ In the cases analyzed 
here, there were no significant differences between the serotype and the occurrence of death. In Brazil, the

Table 1. Characteristics of the sample $(N=118) .^{a}$

\begin{tabular}{|c|c|}
\hline Variable & Result \\
\hline Age, years ${ }^{b}$ & $57(33-72)$ \\
\hline Male gender & $66(55.9)$ \\
\hline \multicolumn{2}{|l|}{ Major manifestation } \\
\hline Pneumonia & $90(76.3)$ \\
\hline Meningitis & $12(10.2)$ \\
\hline Mastoiditis/abdominal abscess & $3(2.5)$ \\
\hline Unknown/other & $14(11.9)$ \\
\hline Mortality & $39(33.1)$ \\
\hline \multicolumn{2}{|l|}{ Culture type } \\
\hline Blood & $101(85.6)$ \\
\hline Cerebrospinal fluid & $15(13.7)$ \\
\hline Abdominal fluid/other & $4(3.4)$ \\
\hline \multicolumn{2}{|l|}{ Clinical comorbidity } \\
\hline Oncologic & $16(13.6)$ \\
\hline Cardiac & $48(40.7)$ \\
\hline Pulmonary & $19(16.1)$ \\
\hline Gastrointestinal & $14(11.9)$ \\
\hline Neurologic & $25(21.2)$ \\
\hline Rheumatologic & $4(3.4)$ \\
\hline Endocrine & $26(22.0)$ \\
\hline Renal & $13(11.0)$ \\
\hline Immunosuppression $^{c}$ & $34(28.8)$ \\
\hline \multicolumn{2}{|l|}{ Use of drugs } \\
\hline \multicolumn{2}{|l|}{ Licit } \\
\hline \multicolumn{2}{|l|}{ Smoking } \\
\hline Yes & $23(19.5)$ \\
\hline No & $54(45.8)$ \\
\hline Former smoker & $4(3.4)$ \\
\hline Unknown & $37(31.4)$ \\
\hline \multicolumn{2}{|l|}{ Alcoholism } \\
\hline Yes & $5(4.2)$ \\
\hline No & $80(67.8)$ \\
\hline Unknown & $33(28.0)$ \\
\hline Illicit & $2(1.7)$ \\
\hline Previous hospital admissions & $58(49.2)$ \\
\hline ICU admission & $41(34.7)$ \\
\hline Use of mechanical ventilation & $28(23.7)$ \\
\hline Tracheostomy & $2(1.7)$ \\
\hline Length of hospital stay, days ${ }^{\mathrm{b}}$ & $10(5-19)$ \\
\hline
\end{tabular}

aValues expressed as $n(\%)$, except where otherwise indicated. 'Values expressed as median (interquartile range). cHIV and/or neoplasm and/or use of corticosteroids and/or use of immunosuppressants. frequency of serotype $20 \mathrm{~B}$ has been increasing, ${ }^{(21)}$ but its detection rate was low in the sample studied here.

In the present study, as shown in Table 3, the theoretical coverage of PPV23 alone and of PCV13 plus PPV23 was $31.4 \%$ and $50.8 \%$, respectively. This means that, theoretically, patients receiving the vaccine combination would have a reduction in the number of IPD cases associated with the serotypes identified in the present study. Andrade et al. ${ }^{(18)}$ and Mott et al. ${ }^{(16)}$ reported a theoretical coverage of PCV13 of $94.1 \%$ and $64.5 \%$, respectively, which is well above our results.

In 1988 , the first case of resistance to penicillin was reported in Brazil, (22) and, in 2006, Camargos et al. published that the 7-valent pneumococcal conjugate vaccine covered $89 \%$ of penicillin-resistant pneumococci and could then help reduce the spread of these strains, thereby decreasing the need for antibiotics. ${ }^{(23)}$ Regardless of the existence of vaccines, increased pneumococcal resistance to penicillin has become worrisome, ${ }^{(16)}$ and, in the future, therapeutic failure may occur when starting empirical antimicrobial therapy. ${ }^{(24)}$

As early as 2006 , Zettler et al. reported a prevalence of penicillin-resistant strains of $22.8 \%$ in cultures of sterile body fluids and sputum. (25) Other Brazilian authors reported finding resistance to penicillin in $13.3 \%$ of the strains and resistance to sulfamethoxazole/ trimethoprim in $37.7 \%$ to $80.0 \%$ of the strains. ${ }^{(16,18)}$ In the present study, these resistances were $9.3 \%$ and $37.3 \%$, respectively, and there was no resistance to vancomycin. Serotypes 9 and 14 appear to be associated with greater resistance to penicillin, ${ }^{(26)}$ a finding that was not observed in the sample studied here.

As has been shown in other studies, ${ }^{(27,28)}$ the most common manifestation of IPD was community-acquired pneumonia ( $n=90 ; 76.3 \%$ ). The pneumococcus is most commonly isolated from blood cultures, ${ }^{(18,29)}$ a finding similar to that of our study $(n=101 ; 85.6 \%)$. When studying comorbidities in the present sample in terms of mortality and need for ICU care and/or MV, we detected no significant differences, and overall mortality in our sample was $33.1 \%(n=39)$.

A crucial part in the treatment of (invasive or noninvasive) pneumococcal disease is the use of antimicrobials, which may be decisive in the course and prognosis of the disease. ${ }^{(30,31)}$ Some authors have suggested that surveillance of only cases that required hospitalization probably underestimates the true socioeconomic costs of IPD. ${ }^{(32)}$ The path to reduce the high morbidity, mortality, ${ }^{(4,33,34)}$ and socioeconomic $\operatorname{costs}^{(3)}$ of the disease must be through prevention.

Table 2. Selected outcomes by presence of comorbidities. ${ }^{a}$

\begin{tabular}{lccc}
\multicolumn{1}{c}{ Outcome } & $\begin{array}{c}\text { With no comorbidities } \\
(\mathbf{n}=\mathbf{2 4 )}\end{array}$ & $\begin{array}{c}\text { With comorbidities } \\
(\mathbf{n}=\mathbf{9 4})\end{array}$ & $\mathbf{p}$ \\
Mortality & $4(16.7)$ & $35(37.2)$ & 0.095 \\
Need for ICU admission & $8(33.3)$ & $33(35.1)$ & 1.000 \\
Need for mechanical ventilation & $5(20.8)$ & $23(24.5)$ & 0.917 \\
Tracheostomy & $1(4.2)$ & $1(1.1)$ & 0.367 \\
\hline
\end{tabular}

avalues expressed as $\mathrm{n}(\%)$. 
Table 3. Theoretical vaccine coverage. ${ }^{\mathrm{a}}$

\begin{tabular}{lcccc} 
Vaccine coverage & $\begin{array}{c}\text { Total sample }^{\text {b }} \\
(\mathbf{N}=\mathbf{1 1 8})\end{array}$ & $\begin{array}{c}\text { Death } \\
(\mathbf{n}=39)\end{array}$ & $\begin{array}{c}\text { Non-death } \\
\text { (n= 77) }\end{array}$ & $\mathbf{p}$ \\
\hline PCV13 alone & $1(0.8)$ & $1(2.6)$ & $0(0.0)$ & 0.508 \\
PPV23 alone & $37(31.4)$ & $12(30.8)$ & $25(32.5)$ & \\
PCV13 plus PPV23 & $60(50.8)$ & $19(48.7)$ & $41(53.2)$ & \\
No coverage & $20(16.9)$ & $7(17.9)$ & $11(14.3)$ & \\
\hline
\end{tabular}

PCV13: 13-valent pneumococcal conjugate vaccine; and PPV23: 23-valent pneumococcal polysaccharide vaccine (PPV23). aValues expressed as $n(\%)$. ${ }^{b}$ Two patients with unknown outcome status (no vaccine coverage). cSerotype 6A. dSerotypes 3, 8, 9N, 10A, 11A, 12F, 15B, 17F, 20, 22F, and 33F.

There is as yet no consensus as to whether it would be possible to replace PPV23 with PCV13 in adults, it being considered that, even without having the highest number of serotypes, PCV13 would be better for the adult population because it produces more antibodies in the long term. ${ }^{(35,36)}$ Some authors disagree with this position, emphasizing that cost-effectiveness studies of vaccination of adults with PCV13 (rather than with PPV23) have been influenced by biases. Among these biases are the low herd effect produced by the use of PCV13 in children and the poor prevention against community-acquired pneumonia resulting from the use of PPV23 in adults with any immunosuppression. (35,37) $^{2}$

Another point to be confirmed is the apparent increased frequency of IPD caused by nonvaccine serotypes in some places, including Brazil.(19) This is believed to be due to the increased number of vaccinated children, with the consequent herd effect, and the progressive replacement of vaccine serotypes with nonvaccine serotypes in the etiology of cases.

The present study was aimed at finding some answers on a more local level, that is, it sought to determine whether the serotypes in our region would match those in other parts of Brazil, establishing a connection between these findings and the theoretical coverage of the two currently available pneumococcal vaccines. Our results reinforce the need for an intensive policy of pneumococcal vaccination not only of children but also of adults 18 years of age or older with comorbidities, as well as of the elderly, in order to reduce the still very high morbidity and mortality associated with IPD, especially in developing countries. $(2,27,29,38,39)$
The importance of the present study lies in it demonstrating that there are several pneumococcal serotypes that caused IPD in our patient sample that are not covered by the current formulations of the available vaccines (in $49.7 \%$ of the cases). This theoretical coverage profile reflects our current situation, which should be compared with that observed in similar studies conducted elsewhere.

Our study had some limitations: serotyping was performed at another affiliated institution; and some samples could not be used in this survey. As a result, the number of cases became smaller than we first expected. In addition, vaccine coverage data were missing from the medical records of most of the cases included. Therefore, we had to evaluate theoretical vaccine coverage, that is, we sought to determine whether the identified serotypes were covered by the available vaccines.

Increased antimicrobial resistance and the existence of great serotype diversity are key elements that should be taken into account when addressing such an important issue in clinical practice: the prevention and treatment of pneumococcal diseases. ${ }^{(40)}$

\section{ACKNOWLEDGMENTS}

The authors are grateful to Professor Maria C. Brandileone at the Adolfo Lutz Institute for her support to this study. The authors are also grateful to Vany Pagnussatti, a microbiologist at the Pontifical Catholic University of Rio Grande do Sul Hospital São Lucas Microbiology Laboratory, for performing the pneumococcal cultures.

\section{REFERENCES}

1. Ferkol T, Schraufnagel D. The global burden of respiratory disease. Ann Am Thorac Soc. 2014;11(3):404-6. https://doi.org/10.1513/ AnnalsATS.201311-405PS

2. Griffin MR, Zhu Y, Moore MR, Whitney CG, Grijalva CG. U.S hospitalizations for pneumonia after a decade of pneumococcal vaccination. N Engl J Med. 2013;369(2):155-63. https://doi. org/10.1056/NEJMoa1209165

3. Welte T, Torres A, Nathwani D. Clinical and economic burden of community-acquired pneumonia among adults in Europe. Thorax. 2012;67(1):71-9. https://doi.org/10.1136/thx.2009.129502

4. Burgos J, Luján M, Larrosa MN, Fontanals D, Bermudo G, Planes AM, et al. Risk factors for respiratory failure in pneumococcal pneumonia: the importance of pneumococcal serotypes [abstract]. Eur Respir J. 2014;43(2):545-53. https://doi.org/10.1183/09031936.00050413

5. Burgos J, Lujan M, Larrosa MN, Pedro-Botet ML, Fontanals $D$ Quesada MD, et al. The problem of early mortality in pneumococcal pneumonia: a study of risk factors. Eur Respir J. 2015;46(2):561-4 https://doi.org/10.1183/09031936.00034415

6. Flego KL, Truman G, Sheppeard V, Gilmour RE. Invasive pneumococcal disease in western Sydney, 2002-2010. N S W Public Health Bull. 2011;22(11-12):219-21. https://doi.org/10.1071/NB11012

7. Tin Tin Htar M, Christopoulou D, Schmitt HJ. Pneumococcal serotype evolution in Western Europe [abstract]. BMC Infect Dis. 2015;15:419. https://doi.org/10.1186/s12879-015-1147-x

8. Huang SS, Johnson KM, Ray GT, Wroe P, Lieu TA, Moore MR, et al. Healthcare utilization and cost of pneumococcal disease in the United States [abstract]. Vaccine. 2011;29(18):3398-412. https://doi. org/10.1016/j.vaccine.2011.02.088

9. Simonsen L, Taylor RJ, Schuck-Paim C, Lustig R, Haber M, Klugman $\mathrm{KP}$. Effect of 13-valent pneumococcal conjugate vaccine on admissions to hospital 2 years after its introduction in the USA: a time series analysis. Lancet Respir Med. 2014;2(5):387-94. https:// 
doi.org/10.1016/S2213-2600(14)70032-3

10. Daniels CC, Rogers PD, Shelton CM. A Review of Pneumococcal Vaccines: Current Polysaccharide Vaccine Recommendations and Future Protein Antigens [abstract]. J Pediatr Pharmacol Ther. 2016;21(1):27-35. https://doi.org/10.5863/1551-6776-21.1.27

11. Dubos R, Avery OT. Decomposition of the capsular polysaccharide of pneumococcus type III by a bacterial enzyme. J Exp Med. 1931;54(1):51-71. https://doi.org/10.1084/jem.54.1.51

12. Avery OT, Dubos R. The protective action of a specific enzyme against type III Pneumococcus infection in mice [abstract]. J Exp Med. 1931;54(1):73-89. https://doi.org/10.1084/jem.54.1.73

13. Jacobs MR, Dagan R. Antimicrobial resistance among pediatric respiratory tract infections: clinical challenges. Semin Pediatr Infect Dis. 2004;15(1):5-20. https://doi.org/10.1053/j.spid.2004.01.003

14. Brasil. Ministério da Saúde. Agência Nacional de Vigilância Sanitária (ANVISA) [homepage on the Internet]. Brasilia: ANVISA [cited 2017 Feb 20l. Padronização dos Testes de Sensibilidade a Antimicrobianos por Disco-difusão: Norma Aprovada - Oitava Edição. 2003. M2A8;23(1) [Adobe Acrobat document, 58p.]. Available from: http:// www.anvisa.gov.br/servicosaude/manuais/clsi/clsi_OPASM2-A8.pdf

15. Mantese OC, Paula Ad, Almeida W, Aguiar PA, Wolkers PC, Alvares $J R$, et al. Prevalence of serotypes and antimicrobial resistance of invasive strains of pneumococcus in children: analysis of 9 years. J Pediatr (Rio J). 2009;85(6):495-502. https://doi.org/10.2223/ JPED.1950

16. Mott M, Caierao J, Rosa da Cunha G, Rodrigues Perez LR, Matusiak R, Pilger de Oliveira KR, et al. Susceptibility profiles and correlation with pneumococcal serotypes soon after implementation of the 10-valent pneumococcal conjugate vaccine in Brazil. Int J Infect Dis. 2014;20:47-51. https://doi.org/10.1016/.i.jid.2013.11.009

17. Leite CR, Azevedo J, Galvão VS, Moreno-Carvalho O, Reis JN, Nascimento-Carvalho C. Clinical and bacteriological characteristics of invasive pneumococcal disease after pneumococcal 10-valent conjugate vaccine implementation in Salvador, Brazil. Braz J Infect Dis. 2016;20(1):56-60. https://doi.org/10.1016/j.bjid.2015.10.005

18. Andrade AL, Oliveira R, Vieira MA, Minamisava R, Pessoa V Jr, Brandileone $\mathrm{MC}$, et al. Population-based surveillance for invasive pneumococcal disease and pneumonia in infants and young children in Goiânia, Brazil. Vaccine. 2012;30(10):1901-9. https://doi. org/10.1016/j.vaccine.2011.12.012

19. Verani JR, Domingues CM, de Moraes JC; Brazilian Pneumococcal Conjugate Vaccine Effectiveness Study Group. Indirect cohort analysis of 10-valent pneumococcal conjugate vaccine effectiveness against vaccine-type and vaccine-related invasive pneumococcal disease. Vaccine. 2015;33(46):6145-8. https://doi.org/10.1016/j. vaccine.2015.10.007

20. Weil-Olivier C, Gaillat J. Can the success of pneumococcal conjugate vaccines for the prevention of pneumococcal diseases in children be extrapolated to adults? Vaccine. 2014;32(18):2022-6. https://doi. org/10.1016/.vaccine.2014.02.008

21. Caierão J, Sant'Anna FH, Hawkins P, Cunha GR, Mott M, Falci DR, et al. Characteristics of serogroup 20 S.pneumoniae isolates from Brazil. BMC Infect Dis. 2016;16(1):418. https://doi.org/10.1186/ s12879-016-1773-y

22. de Sousa Marques HH, Yamamoto M, Sakane PT, Caiaffa-Filho HH, Figueiredo Mendes CM. Relatively penicillin-resistant pneumococcal meningitis in a Brazilian infant. Pediatr Infect Dis J. 1988;7(6):433-4. https://doi.org/10.1097/00006454-198806000-00017

23. Camargos P, Fischer GB, Mocelin H, Dias C, Ruvinsky R. Penicillin resistance and serotyping of Streptococcus pneumoniae in Latin America. Paediatr Respir Rev. 2006;7(3):209-14. https://doi. org/10.1016/j.prrv.2006.04.004

24. Jones RN, Jacobs MR, Sader HS. Evolving trends in Streptococcus pneumoniae resistance: implications for therapy of communityacquired bacterial pneumonia. Int J Antimicrob Agent. 2010;36(3):197204. https://doi.org/10.1016/j.ijantimicag.2010.04.013

25. Zettler EW, Scheibe RM, Dias CA, Santafé P, Santos DS, Moreira Jda $S$, et al. Determination of penicillin resistance in Streptococcus pneumoniae isolates from southern Brazil by PCR. Int J Infect Dis. 2006;10(2):110-5. https://doi.org/10.1016/j.ijid.2005.04.005

26. Pinto TC, Kegele FC, Dias CA, Barros RR, Peralta JM, Merquior VL, et al. Streptococcus pneumoniae Serotypes 9 and 14 Circulating in
Brazil over a 23-Year Period Prior to Introduction of the 10-Valent Pneumococcal Conjugate Vaccine: Role of International Clones in the Evolution of Antimicrobial Resistance and Description of a Nove Genotype. Antimicrob Agents Chemother. 2016;60(11):6664-6672 https://doi.org/10.1128/AAC.00673-16

27. Drijkoningen JJC, Rohde GGU. Pneumococcal infection in adults: burden of disease. Clin Microbiol Infect. 2014;20 Suppl 5:45-51. https://doi.org/10.1111/1469-0691.12461

28. Stamboulian D, Vazquez $H$, Confalonieri V, Bradileone MC, Kfouri R, Corso A. Multicenter Retrospective Study on Streptococcus pneumoniae Serotypes isolated from Adult Patients with Invasive Pneumococcal Disease in Latin America labstract panel on the Internet]. Philadelphia, PA: ID Week 2014; 2014 Oct 11 [cited 2017 Jan 20]. Available from: https://idsa.confex.com/idsa/2014/ webprogram/Paper47038.html

29. Domingues CM, Verani JR, Montenegro Renoiner El, de Cunto Brandileone MC, Flannery B, de Oliveira LH, et al. Effectiveness of ten-valent pneumococcal conjugate vaccine against invasive pneumococcal disease in Brazil: a matched case-control study. Lancet Respir Med. 2014;2(6):464-71. https://doi.org/10.1016/S22132600(14)70060-8

30. Dellinger RP, Levy MM, Carlet JM, Bion J, Parker MM, Jaeschke $R$, et al. Surviving Sepsis Campaign: international guidelines for management of severe sepsis and septic shock: 2008. Crit Care Med. 2008;36(1):296-327. Erratum in: Crit Care Med. 2008;36(4):1394-6. https://doi.org/10.1097/01.CCM.0000298158.12101.41

31. Uppu DS, Ghosh C, Haldar J. Surviving sepsis in the era of antibiotic resistance: are there any alternative approaches to antibiotic therapy? Microb Pathog. 2015;80:7-13. https://doi.org/10.1016/j. micpath.2015.02.001

32. Andrade AL, Silva SA, Martelli CM, Oliveira RM, Morais Neto OL, Siqueira Júnior JB, et al. Population-based surveillance of pediatric pneumonia: use of spatial analysis in an urban area of Central Brazil. Cad Saude Publica. 2004;20(2):411-21. https://doi.org/10.1590/ S0102-311X2004000200008

33. Lozano R, Naghavi M, Foreman K, Lim S, Shibuya K, Aboyans

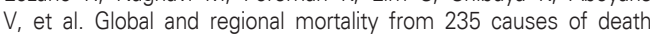
for 20 age groups in 1990 and 2010: a systematic analysis for the Global Burden of Disease Study 2010. [Internet]. Vol. 380 Lancet. 2012;380(9859):2095-128. https://doi.org/10.1016/S01406736(12)61728-0

34. Naucler P, Darenberg J, Morfeldt E, Ortqvist A, Henriques Normark B. Contribution of host, bacterial factors and antibiotic treatment to mortality in adult patients with bacteraemic pneumococcal pneumonia. Thorax. 2013;68(6):571-9. https://doi.org/10.1136/ thoraxjn-2012-203106

35. Esposito S, Principi N. Pneumococcal vaccines and the prevention of community-acquired pneumonia. Pulm Pharmacol Ther. 2015;32:124-9. https://doi.org/10.1016/..pupt.2014.02.003

36. Fedson DS, Guppy MJ. Pneumococcal vaccination of older adults: conjugate or polysaccharide? Hum Vaccines Immunother. 2013;9(6):1382-4. https://doi.org/10.4161/hv.24692

37. Moberley S, Holden J, Tatham DP, Andrews RM. Vaccines for preventing pneumococcal infection in adults. Cochrane Database Syst Rev. 2013;(1):CD000422. https://doi.org/10.1002/14651858. CD000422.pub3

38. Scotta MC, Veras TN, Klein PC, Tronco V, Polack FP, Mattiello $\mathrm{R}$, et al. Impact of 10-valent pneumococcal non-typeable Haemophilus influenzae protein D conjugate vaccine (PHiD-CV) on childhood pneumonia hospitalizations in Brazil two years after introduction. Vaccine. 2014;32(35):4495-9. https://doi.org/10.1016/j. vaccine.2014.06.042

39. Diaz J, Terrazas S, Bierrenbach AL, Toscano CM, Alencar GP, Alvarez $A$, et al. Effectiveness of the 10-Valent Pneumococcal Conjugate Vaccine (PCV-10) in Children in Chile: A Nested Case-Control Study Using Nationwide Pneumonia Morbidity and Mortality Surveillance Data. PLoS One. 2016;11(4):e0153141. https://doi.org/10.1371/ journal.pone. 0153141

40. Tali-Maamar H, Laliam R, Bentchouala C, Touati D, Sababou K, Azrou S, et al. Reprint of: Serotyping and antibiotic susceptibility of Streptococcus pneumoniae strains isolated in Algeria from 2001 to 2010. Vaccine. 2012;30 Suppl 6:G25-31. https://doi.org/10.1016/j. vaccine.2012.11.019 